\title{
TRES TRISTES RELATOS DE UN ALEGRE PUEBLO
}

\section{Three sad stories of a cheerful people}

\author{
Ernesto Monroy-González*
}

Recibido:21 de mayo 2020. Aceptado: 28 de junio de 2020. Publicado: 01 de julio 2020.

\begin{abstract}
Forma de citar este artículo en APA:
Monroy-González, E., (2020, julio-diciembre). Tres tristes relatos de un alegre pueblo. Revista CoPaLa, Construyendo Paz.

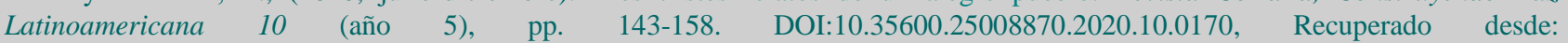
http://revistaconala.net/index.php/ois/article/view/9

\section{Resumen}

El presente artículo, procura abrir un espacio de reflexión sobre diferentes situaciones vividas en él departamento del Tolima, municipio de Chaparral, en el cual la violencia sin control, la muerte de campesinos inocentes y la amargura de un pueblo, marcó diferentes momentos en la vida de esas ingenuas personas.

Se apoya metodológicamente, en la descripción narrativa de diferentes actores que vivieron dichos amargos tiempos, tomando de ellos el relato sin modificación alguna, enmarcado dentro de la línea temática de investigación popular, comunitaria, militante y participativa.

Se espera que, de alguna u otra forma, logre revelar las atrocidades de la guerra y la violencia, las consecuencias de vivir en una agonía permanente, por existir en la cordillera, él plan o entre las dos partes, por su creencia o por ser objetivo de las cuotas de efectividad de los que dicen defender la ley.

\section{Palabras clave}

Violencia, campesinos, muerte, personas, ley.

Tecnólogo Agropecuario, Administrador de Empresas Agropecuarias, Especialista en Gerencia de Proyectos, egresado de la Maestría en Desarrollo Rural de la Universidad del Tolima. Par Académico del Ministerio de Educación Nacional, Profesor Universitario y Directivo Académico, con más de 15 años de experiencia. Extensionista y Consultor Efectivo de Colciencias. Asesor para el desarrollo de la ruralidad.. emonroy@ut.edu.co 


\section{Abstract}

This article seeks to open a space for reflection on different situations experienced in the department of Tolima, municipality of Chaparral, in which violence without control, the death of innocent peasants and the bitterness of a people, marked different moments in the lives of those naive people.

It is supported methodologically, in the narrative description of different actors who lived such bitter times, taking from them the story without any modification, framed within the thematic line of popular, community, militant and participative research.

It is hoped that, in one way or another, he will succeed in revealing the atrocities of war and violence, the consequences of living in permanent agony, existing in the mountain range, the plan or between the two parties, by their bélief or by being targeted by the quotas of effectiveness of those who claim to uphold the law.

\section{Keywords}

Violence, peasants, death, people, law. 
Este artículo, pertenece a la visualización y avances del resultado del trabajo de grado en Maestría en Desarrollo Rural titulada, Actividad y Desarrollo de las Asociaciones Campesinas Agropecuarias: Un Estudio de Caso en el Municipio de Chaparral - Tolima, y en la cual se realizaron diferentes encuentros con los campesinos y habitantes del sector rural de la región del Cañón de las Hermosas, de tal manera que mediante él mismo se le hace honor a la narrativa y su lenguaje natural, como un aporte significativo para la construcción de paz, mediante el recuento de sus propias vivencias, las anécdotas que marcaron a diferentes actores y desde diferentes escenarios, bajo él entendido que fueron muchos las variables que se conjugaron y que influenciaron en diferentes formas, la cotidianidad de los habitantes e mención, participando unos activa y directamente y otros a través de la intencionalidad de terceras personas u organizaciones con diferentes tendencias ideológicas o simplemente intereses personales, políticos, religiosos y hasta gubernamentales.

A través de estos relatos, se podrán evidenciar múltiples eventos que impactaron a la población, que modificaron su sistema de vida, la tranquilidad y armonía de sus pobladores, pero especialmente, la modelación del carácter productivo, frente a la necesidad de sobrevivir, de salir adelante y por qué no decirlo, hasta de defenderse, proteger a sus familias y la oportunidad de seguir haciendo presencia en sus tierras, adquiridas en gran parte por tradición, con esfuerzos y sacrificios de generaciones anteriores que le aportaron al crecimiento regional y el posicionamiento de la localidad en niveles muy destacados para él sector rural en toda la nación, a través de las organizaciones sociales sin ánimo de lucro, pero con fines y objetivos en común, por agrupación de ciudadanos, que se fueron fortaleciendo para hacerle frente y en cierta forma para resguardarse de las diferentes arremetidas, que día a día se hacían más frecuentes y contundentes y sin identificar ni de dónde venían.

Por facilidad, se harán los recuentos literalmente como fueron recaudados, solamente adicionándole un título que identifique a cada uno de ellos especialmente por alguna característica que lo identifique y modificando los nombres que quien participaron, en tal sentido, se inicia con la narración de la señora Matilde, quien perdió en la vereda de San Jorge Alto a su familia, a manos de la guerrilla y otros, como a continuación se describen. (Monroy, 2018). 


\section{"A la Derecha del Señor"}

"Yo vivía cerca al pueblo, en una finca que se llamaba él Encanto, mis padres durante más de cuarenta años, fueron labrando la tierra con mucho amor, esas tierras eran la heriencia que le dejó mi abuélo materno a mi amá, quien con mucho sacrifico le tocaba que desplazarse por varios lugares para ir trabajando y así conseguir algo de plata y así ayudarle a mi apá para él sustento de todos nosotros. Fuimos en total 4 hombre y 3 mujeres y habemos 4 vivos, 2 hombres y dos mujeres porque los otros los mataron al igual que a mis dos hijos y mi esposo, dizque por ser informante de los paracos. En la finca, siempre se respetaba la palabra de Dios, mi apá era muy creyente y mi amá ni hablar, élla todos los domingos nos llevaba a misa, recuerdo que era la chorrera de chinitos, agarrados todos de las manos, recién bañaditos y oliendo a palmolive y con la mejor pinta, que siempre nos la guardaban los viejos para esa célebración.

En la finca se producía café, plátano en la parte baja, yuca, frutales y también se tenía algunas vacas pa la leche y aveces mi apá negociaba alguna pa carne en el pueblo, aunque prefería hacerlo en Chaparral, claro que, con mayor dificultad, porque le costaba más dinero el desplazamiento al igual que la res cuando la llevaba, que por lo regular era solamente una. Yo me quedé con la finca, porque logré negociar con mis hermanos y hermanas, poco a poco los lotecitos que le habían dado a cada uno de ellos, además también poco a poco se fueron haciendo a diferentes predios en otros lugares y le concentraron mayor atención a los mismos, esos berracos no le prestaban el tiempo que se requería para poder ponerla a producir y los hombres eran muy chivos y tomatragos, les gustaba la parranda, las viejas y hasta pélioneros.

Nosotros no teníamos ninguna afiliación política, no nos interesaba nada de esas cosas, aunque ni apá y amá eran liberales y mi esposo también decía que era eso, aunque no sabía ni para que servía serlo o no serlo. Ese cuento de la política solamente se hacía repetitivo cada vez que los candidatos querían llegar a ocupar algún cargo, ahí si llegaban y eran atentos, saludaban con alegría y como si fueran miembros de la familia de uno, pero después ni en las curvas, al igual que lo que prometían que por su puesto nunca cumplían, todo era puro cuento, pero así estábamos acostumbrados todos en mi pueblo y en la región, habemos muchos pendejos que todavía le creen a esos mentirosos. Es más, uno de ellos, nos metió en un problema una vez con unos vecinos, porque nosotros no nos interesaba y él quería llegar a la alcaldía, eso fue como en él año 92 si más no recuerdo, y cuando fue a la finca, nos mencionó a don Argemiro, él vecino, nos dijo que él lo estaba apoyando con toda su familia, yo no sé porque lo hizo al nombrarlo, puesto que en realidad nosotros si éramos muy amigos del señor, seguramente por eso fue que lo hizo, alguien le dijo que con eso nos 
convencería. Cuando sucedió eso, mi esposo se hizo él bobo, no le comió bombo y no lo apoyó, más aún, le dijo a ese señor aspirante a la alcaldía de apellido,

Alvira creo, que no nos importaba que fuera amigo de don Argemiro y eso fue suficiente para que la amistad se terminara con él vecino, porque sin duda alguna el candidato de alguna forma le contó eso al señor y nunca preguntó nada sobre lo sucedido, pero cambió la actitud por completo y paso de ser amigo a nuestro enemigo. Este vecino después de eso nos negó la toma de agua que teníamos en los linderos de su predio, que era más alto lo que nos facilitaba que llegar mejor presión, nos tocó que ponerla dentro del nuestro, pero más abajo y se disminuyó mucho él chorro y la fuerza con la que llegaba, de tal forma que antes servía él chorro hasta para los cultivos y después a duras penas para la casa. Mi esposo frente a todo esto, nunca le hizo reclamo ni nada, él no era de problemas, pero si era muy orgulloso y no le rendía pletecia a nadies. Con ese vecino se fueron agravando las cosas, él nos corría la cerca cada nada, se hacia el pendejo y nos mataba gallinas sueltas que se le cruzaban a su finca. Una vez, cuando el gobierno llegó promocionando ese insecticida que era tan malo, para acabar la amapola, él tal gris fosfato, el aplicó en la parte baja sin ningún control y fuera de eso hasta sin permiso de la guerrilla, porque para eso tenía que pedir permiso y ni puél chiras, decir que era pa la amapola, había que decir que era para la maleza, aunque por debajo de cuerda se sabía que los que hacían eso recibían de la alcaldía un dinero como premio a cambio. Cuando él lo hizo, no le importó acabarnos con unas maticas de lulo y mora que se alcanzaban a dar en esa altura, mi marido, solamente le hizo un comentario sobre lo sucedido al presidente de la junta, pero hay juepuerca, eso fue suficiente para que ese señor nos cogiera más odio y en adelante, todo lo quería arreglar con la guerrilla, poniendo quejas por todo al comandante Tito, que era el que más presencia hacía en todos lados.

Las cosas fueron cambiando, cada nada se escuchaban ráfagas de fusil o metralleta, cañonazos y problemas delicados para salir, le contaban a uno que la guerrilla había matado a tantos, que el ejército también, que los paracos iban a subir, mejor dicho, situaciones muy complicadas que aunque desde que yo me conozco se habían presentado, ahora eran más frecuentes y con mayor gravedad, a tal punto que muchas veces ya no podía uno dormir tranquilamente como siempre lo hacíamos, eso sin contar que las amenazas fueron más frecuentes, lo que ocasionó que muchos vecinos se fueran de sus tierras, algunos dejaron botado todo, otros vendieron a precio de huevo a personas que venían protegidas por la guerrilla y que no eran muy amigables, porque no salían de ahí para nada y no participaban de ninguna de las actividades de la junta de acción comunal. Llegó a tal punto la situación, que a lo último ya no se podía salir después de las 6 de la tarde y él que lo 
hiciera corría con él riesgo que lo mataran, o que se lo llevaran en él mejor de los casos detenido para que hiciera sus descargos ante él comandante, quien por lo regular les colocaba en él mejor de los casos trabajos comunitarios como desyerbar caminos, tapar huecos en la vía, arreglar alcantarillas y demás. Las noches eran tan malucas ya, que a veces estaba uno durmiendo cuando sonaba un avión bajito, así como cuando uno está cerca de un colibrí y escucha su run run y él cuento era que él avión fantasma estaba haciendo rondas, y sí; varias veces después que pasaba, se oían las balaceras más bravas, esa noche sabía uno que al otro día iban a haber muchos muertos, como efectivamente sucedía. Una vez, mataron como a 20 por él lado del Davis, todos ellos decían que eran guerrilleros, aunque ahí cayeron varios conocidos que nosotros sabíamos que no lo eran, como él caso de Matías, el hijo del fiscal de la asociación Agritol, que quedó hecho papilla por las balas cuando estaba durmiendo, imagínese que le perforaron él techo a punta de plomo, lo único que lo guardaban eran las tejas de zinc y otras de eternit, eso no servía de nada porque ese aparato era muy bravo lo que hacía y eso que era alto, porque otras veces era con hélicópteros que volaban más bajo.

Se llegó a una situación tan fea, que a lo último ya no se tenía vecinos, amigos ni nada, era solamente estar en su finca, con tierra, pero sin ningún apoyo, lo que tenía obligabo a mis hijos y esposo a alquilarse por el jornal del día, en los morales, en sauces y otras fincas que eran verdaderamente grandes, dejando abandonado todo el trabajo en la finca propia.

Yo creo, que los problemas para nosotros se fueron poniendo más duros cuando se inició todo con don Argemiro, ese señor nos hizo mucho daño, además de las cosas que fueron sucediendo poco a poco, todo se convertía en permisos y permisos con la guerrilla, para tumbar un arbolito que se necesitaba para una cerca, para construir un camino, para tomar agua de la quebrada, para criar pollos, para salir y hasta para hacer fiestas en la casa, o mejor fiestas no, simplemente reuniones para jugar tejo en unas canchas que mi esposo había hecho y que era la única entretención en los fines de semana.

El peor de los momentos en mi vida, fue un viernes 22 de febrero del año 2002, eran como las 7 de la mañana, cuando llegaron a la finca unos guerrilleros, entre esos uno que le decían frijolito, era chiquitico, pero de muy mala fama, nosotros sabíamos que ese señor cuando hacía rondas era vueltas muy jodidas, que terminaban casi siempre en muertos. Desde que llegaron, eran ultrajándonos, mi esposo trató como de mediar un poco y les ofreció café, de nada sirvió, le decían 
jodieron de un golpe y le dieron muchas patadas en él piso, yo gritaba como loca, les decía que no nos fueran a hacer nada, pero no, esa gente no entiende de nada, a ellos tres los amarraron de pies y manos y a mí me amarraron las manos, mi esposo les decía que ellos no se metían con nadie, que ellos eran personas de bien, sin embargo, aun así lo seguían ofendiendo de palabra y en algunas ocasiones con algún golpe. Yo me di cuenta de que en algo tenía que ver el señor Argemiro, el que fue nuestro buen vecino y después nuestro enemigo, porque uno de ellos, no se quien, dijo es que ustedes son sapos y desde hace mucho rato los hemos venido siguiendo. Luego de un buen rato que hablaban en voz baja entre ellos, uno se me acercó junto al que le decían frijolito, me preguntaron que yo a quien pertenecía y que de que bando era, yo no acaté sino decirle que no pertenecía a ningún bando y que solamente lo que sabía era que yo estaba a la diestra de Nuestro Señor, lo que le causó una gran rabia al señor que acompañaba a frijolito y me dijo con razón, esta es una goda hijueputa, y les disparó a mi esposo y mis dos hijos a cada uno de ellos en la cabeza, yo me salvé, porque ellos dijeron que me dejaban para que les contara a todos los godos, lo que les pasaba por ser de derecha."

El departamento del Tolima caracterizó fatídicamente su topografía, una época en la que estar en el plan era disponer de una marcada presencia de grupos de derecha ilegales, denominados autodefensas, denominadas por el común como paramilitares o paracos, estar entre el plan y la cordillera era tener presencia marcada de ejército, que servía como filtro para las entradas y salidas de dichas localidades y estar en la cordillera era estar en lugares con marcada presencia de guerrilla.

Una de las veredas, Florestal Ambeima, era visitada por esos grupos al margen de la ley, con alguna regularidad, pero con mayor frecuencia por los paramilitares, quienes hacían sus pasadas preguntando por los posibles milicianos de la guerrilla, colaboradores o simplemente simpatizantes. Los pobladores salían a la ciudad capital del departamento es decir Ibagué, normalmente los lunes, puesto que era él momento en que los alcaldes eran atendidos en la gobernación del departamento y había cierta posibilidad de viajar con mayor facilidad, da tal manera que muchos campesinos y habitantes del sector rural, dejaban sus fincas o parcélas con alguna persona cuidándolas o simplemente solas, puesto que la delincuencia común no era muy frecuente en la localidad. A continuación, se describe el rélato de la señora Marina, esposa del señor Marcos, un finquero, bonachón y buen vecino. (Monroy, 2018). 


\section{"Yo No Sé Nada"}

"Las actividades que se desarrollaban en la finca, eran fundamentalmente la producción de plátano de muy buena calidad por ser de vega, guayaba en buena cantidad, puesto que él lugar en donde se encontraba ubicada era un poco más caliente y adecuado para las condiciones de dicho cultivo, que abastecía algunas fábricas de bocadillo véleño, como es conocido en todo el Tolima y en muchas partes de Colombia. También se producía queso en diferentes presentaciones, costeño y campesino y se vendía suero para la crianza de cerdos, es decir; era una propiedad que daba buenos ingresos, suficientes para mantener a toda la familia, que estaba compuesta por los cuatro hijos que tuvimos y los que partirían a raíz de los hechos fatídicos que se presentaron, de verdad de forma tan injusta que todavía no termino de entender él ¿por qué tanto dolor sin necesidad?.

Además de todas esas actividades, en la casa de la finca, mi esposo había instalado un billar, por estar ubicada al borde de carretera, al cual iban muchos vecinos y amigos regularmente, a excepción del lunes, que era él que todos conocían como él día del zapatero, puesto que aparentemente no se hacía nada, cuando en realidad se utilizaba para viajar o realizar diligencias fuera de los predios, prioritariamente en Ibagué.

Mi esposo, no tenía ninguna ideología política ni le gustaba nada que tuviera que ver con eso, aunque si se inclinaba mucho por las ideas de Gaitán y por toda su historia, además de ser un ser humano que le gustaba colaborarle a la gente, a todos sin distingo alguno lo que le hizo merecedor de todo el respeto de los habitantes y hasta de los mismos grupos al margen de la ley.

Nosotros, nos dividíamos las actividades entre todos, los hijos ya estaban grandes, tres hombres y una mujer y las actividades del billar, eran atendidas por mi esposo, Marcos, porque él era el que tenía mayor acercamiento con todos los que lo visitaban. En dicho lugar, se hacían tertulias al calor de los aguardientes y en él desarrollo de los chicos de billar que se pactaban, se acordaban apuestas a pierde y paga, cantina libre, libre con nudo, solo libre y diferentes formas que hacían que él tiempo pasara rápidamente. No se descontaba alguno que otro problema, cuando ya habían algunos borrachitos, o sencillamente porque se péleaba porque hubo o no carambola, porque hubo o no pélo y todo eso, pero eran conflictos momentáneos que no repercutían a mayores, incluso cuando se hablaba de política, porque era él lugar predilecto para todos hacerlo y para los encuentros y 

gente, porque eso era lo que hacían, pa que vamos a hablar carreta.

Mi esposo por su admiración a Gaitán y en cierta forma por la manera de ser, casi siempre le daba la entrada a políticos del partido Liberal y muy poco a los conservadores, lo que de alguna forma lo fue identificando como si fuera de ese grupo, hechos que le originaron cierta imagen ante todos los que se lanzaban por dicho partido, para tenerlo en cuenta en sus campañas, aunque muy pocas veces lo consultaban para eso y de las poquitas que lo hicieron, solamente les manifestaba que él no se metía en esos cuentos, pero que les prestaba el lugar. Para estas actividades, mi esposo ya había comprado un altavoz, unos parlantes y un aparto que le servía como para iluminar el lugar donde se ubicaban los candidatos. Creo que el nunca manifestó su interés por la política, pero yo también creo que le gustaba de alguna forma participar en esa joda.

A veces se daba uno cuenta que renegaba por tanto robo, él decía que mientras haiga tanta podredumbre, los frutos serán amargos, que eso era lo que le pasaba a este país en donde de nada valía lo que Gaitán había enseñado, claro está que tampoco le escucha muchas cosas sobre él, creo que solamente él seguía a ese señor por las vainas que en algún momento puaya le mostraron cuando vivió en el norte del Tolima, y que se formó el tropel por la muerte de Gaitán.

Junto a la finca, había un señor de apéllido Martínez, que era muy pendenciero, le gustaba mucho discutir, tomar trago y jugar billar y como no era un buen jugador, entonces terminaba perdiendo casi siempre plata en las apuestas, lo que con el trago se convertía en un problema, porque muchas veces terminaban agarrados paliando porque no le aceptaban sus pataletas. Una vez, Marcos intervino para que no lo pelaran a punta de machete, porque se montó en el bus que no era y se agarró a paliar con un mancito que decían que era informante de la guerrilla, para lo que Marcos pues lógico que no dejó que lo jodieran, pero él cucho ese no lo entendió de esa forma y se fue diciéndole collarejo marica a Marcos, sin obtener respuesta de él porque no le gustaban los problemas, como dicen él era muy bueno para estar agarrado peleando con todo el que se le atravesara y para el negocio tampoco era bueno eso. Curiosamente el viejo Martínez, era todo un caballero cuando estaba en sano juicio y ahí sí muy callado, a él le decían el apóstol, nunca supe por qué, pero ese apodo venía de mucho tiempo atrás quienes lo conocían y no lo relacionaban con algo bueno. 


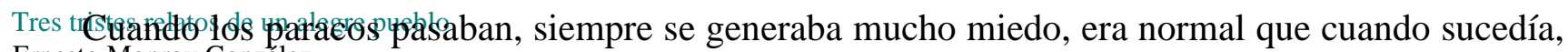
Ernesto Monroy González

no había ejército, todos sabian que eso no era casualidad, lo que originaba más miedo en todo el mundo, porque siempre que iban a llegar, desaparecía la ley.

El lunes agosto 7 del 2000, Marcos viajó a Ibagué, dejó cerrado él billar, y la finca quedó en manos de los hijos, él madrugó y se echó todo el día allá, yo lo acompañé, aunque la verdad no estuve con él en todo momento porque yo quería comprar unas telas para mirar a ver si hacía unos vestidos, yo cosía algo de ropa, ya no lo hago. Nos vinimos en el último bus que sale a chaparral y nos recogieron en moto dos amigos para llevarnos a la vereda, porque cuando llegamos a esa hora ya caída la noche, no había forma de transportarnos, el toque de queda que la guerrilla hacía después de las 6 de la tarde, no contaba para ese sector, por lo que les comento era de influencia de los paracos, sin embargo, era necesario hacerlo con precaución, eso lo había arreglado bien mi esposo. Cuando llegamos a eso de las 9 de la noche, solamente lo que hicimos fue comer algo, de lo que nos habían dejado los hijos guardado y nos acostamos para madrugar a la rutina de todos los días.

El martes 8, nos levantamos para iniciar las labores, como siempre, él se fue para el billar a limpiar mesas, que, aunque estuvo cerrado el día anterior, siempre acumulaban polvo por lo de la carretera que pasaban muchos jeep y levantaban tierra, no solo a las mesas sino a todo el local. A Marcos le gustaba mucho dedicarse a esa labor y en horas de la tarde o si le quedaba un espacio, se metía un poquito en la finca para mirar otras cosas. Yo, por mi parte me dediqué a la cocina, a las tareas de la casa, mis hijos como cosa curiosa madrugaron, pero se fueron cada uno a sus diferentes labores, entre esas viajar cerca a otra finca donde un señor a arreglar en conjunto con otros propietarios la toma de agua, que se había tapado días anteriores por un derrumbe y no dejaba pasar a los predios, sin contar el peligro por llenarse tanto en forma represada. Es decir: todos de alguna forma quedamos desconectados, a excepción de Marcos y yo que seguimos en la casa. Yo preparé la comida y les tapé a mis hijos, en horas de la tarde salí un momento para la vereda, que nos quedaba un poco cerca, es decir; la finca era cerca a la vereda, pero no dentro de ella, estaba más o menos a 15 minutos caminando, por buena vía. Yo me fui engomada por lo de las telas, a buscar a una señora que siempre me cosía la ropa y que me podía dar luces para que no la embarrara, porque yo quería hacerlo con dos cortes que me traje de Ibagué él día anterior.

Marcos, en horas de la tarde, a eso de las 3 abrió el billar, estando allí llegó un grupo armado hasta los dientes, muy malas personas, al parecer eran los mismos que habían estado en Montoso, es decir; no era tanta habladuría sobre él rumor de lo que pasó allí. Le preguntaron a Marcos, que, si 
él había visto la guerrilla o algo raro el día anterior y el sencillamente dijonoșistsinelaçatarudeciglesueblo

que era que no había estado en el billar y que había viajado a lbagué. Ellos se fueron, lo que de

alguna forma tranquilizó a mi esposo, sin embargo, como a eso de los 10 minutos, regresaron, pero ya con una actitud más agresiva y ya aterradora al parecer, porque él estaba completamente solo,

puesto que los hijos menos mal no habían llegado de la finca en dónde estaban trabajando en la toma de agua, ni tampoco muchos vecinos que también estaban en dicha actividad, lo hizo enfrentar solo todo. Luego nos enteramos de que como a él le habían preguntado que, si el día anterior había pasado la guerrilla o había sucedido algo raro por ahí y respondió la verdad... yo no sé nada. Ellos le hicieron la misma pregunta al viejo Martínez que vivía más arriba de la casa, a lo que respondió que sí, puesto que él si había estado el lunes ahí y si vio a la guerrilla pasar, que ellos si habían estado el lunes, que habían reunido algunas personas para advertirlos de unas cosas y se fueron, lo que les originó mucha rabia a los paracos y se devolvieron para golpearlo y darle 4 disparos que lo dejaron muerto de una. Lo recogieron y lo echaron en un jeep en donde llevaban más gente muerta y siguieron para el pueblo. Yo estaba en donde la señora Blanca, la modista que me estaba orientando cuando llegó todo el mundo corriendo sin saber para dónde coger, gritando Vinen los paracos y vienen putos matando a todo el que se les atraviese, la verdad yo no sabía qué hacer, si quedarme ahí donde la señora o salir corriendo, pero dije y para dónde, me acordé de Marcos, pero me tranquilicé porque yo sabía que él no se metía en cosas, desconociendo que ya lo traían muerto en la camioneta. Cuando ellos llegaron a la vereda, se hicieron en una plazoleta y hacían disparos al aire, le dijeron a todos los que estábamos aterrorizados en las casa que salieran o los sacaban, de tal forma que la señora Blanca y yo salimos, para darme cuenta que en la camioneta encima de todos esos cuerpos estaba el de mi esposo Marcos, claro él fue el último que mataron en el camino hacia el pueblo, yo salí corriendo hacia el carro, sin importarme nada en esos momentos, gritaba como loca y la gente se dio cuenta que era Marcos, uno de esos matones se me acercó y me dijo que era yo de él, a lo que le dije que mi esposo, hecho que le enfureció al tipo y me dijo a entonces usted es otra igual y de las mismas, que le gusta ocultar a esos hijueputas guerrilleros, yo lejos de imaginarme por qué lo preguntaba. Aterrada, solo le dije no señor, no sé por qué dice eso y uno de ellos dijo pues porque se hizo el marica cuando le preguntamos sobre la visita de sus amiguitos de la guerrilla ayer aquí y si no es por el vecino no nos damos cuenta, y usted también se está haciendo la pendeja, yo solo le respondí...yo no sé nada.”

El imaginario de los Campesinos, lo construyen ellos más con la realidad que con intenciones. Bajo esta premisa, se soporta que en definitiva, son más los eventos que tienen que sortear en el día a día, en la consecución de su sustento, en el afán de labrar la tierra como una actividad sagrada y en la incertidumbre de 


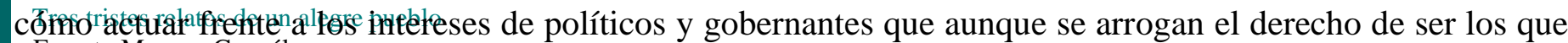
Ernesto Monroy González

cambian el destino de los pueblos, evaden las responsabilidades cuando los resultados no los favorecen, que la construcción o la proyección de un futuro en el que se incluya sus familias y seres queridos, que esté mediado por la educación como principal factor de desarrollo, la inversión social, el crecimiento cultural y demás. Ello

no implica, que no tengan imaginarios, lo que realmente sucede es que las presiones externas de la sociedad y de los agentes transmisores de poder, no les dan tiempo ni espacios para que puedan desarrollar ese imaginario, ese futuro que por el contrario se ve limitado y enredado en un presente no muy halagüeño, curiosamente con la posibilidad que fueran ellos los seres humanos más propensos a disponer de un porvenir, por las condiciones mismas del paisaje, la calidad del aíre y el valor de sus moradores.

Una de las actividades entre tantas, que se ejecutan en el sustento diario en el sector rural, es la producción de leche, el ordeño, la recolección y comercialización en cantinas de 20 litros, en su gran mayoría, destinada para quesos o simplemente para el abastecimiento de industrias de mayor envergadura en donde la pasterizan y embolsan para la venta.

Indudablemente todo en el campo es diferente a la ciudad, hasta la confianza misma, hecho que se logra observar en la comercialización y otros productos agropecuarios, en los que solamente se sacan las cargas a borde de carretera, para que al cabo de un tiempo pase el jeep recolector y lo suba para ser entregado. Esto sucede igualmente con la leche, pero hay encargados de sacarla desde los puntos de ordeño en las fincas, hasta la carretera, a través de diferentes medios de transporte, a lomo de mula cuando son muchas o sencillamente a hombro cuando es una cantina. A continuación, se presenta el relato del señor Francisco, productor de leche en la vereda Aguas Claras, quien durante muchos años utilizó los servicios de Vladimir, un muchacho con algunas limitaciones mentales, pero de una condición física muy buena, que a pesar de su problema era el sustento de su familia, su madre doña Flor y una hermanita menor llamada Clarita.

\section{"El Lechero"}

"Vladimir, era un muchacho muy bueno, un poco despistado o mejor muy despistado por su condición mental, pero sin maldad en su corazón, es más hasta ingenuo por completo. Él gozaba del amor de todos los pueblerinos, porque sabían quién era y que hacía, además de ser una persona que por todo se reía y a todo le ponía color.

Según se le escucha a doña Flor, ella tuvo problemas cuando nació porque venía enredado en el cordón umbilical, lo que le hizo tardar mucho para parirlo y al parecer se le jodió la cabeza por falta de oxígeno, sin embargo, su salud y estado físico era envidiable, incluso por la misma 
actividad que hacía, cargando cantinas, de leche que no son muy liviainastréesdebips naejorlessonueblo

verracamente pesadas, bultiando café y todo lo que fuera carga, ese man parecía una mula, no le

dolía nada pa echarse encima la 8 arrobas desde el piso y moverse hasta 1 kilómetro o más, yo sé que nadies en toda la vereda lo hacía, solamente él. Vladimir, se hacía su plática, cada uno le pagaba

por cargar, aunque no era mucho, algunas personas se aprovechaban de su ingenuidad y hasta le daban en la cabeza y le pagaban poquito o le ponían mucha carga o varias veces para que cargara, cosas que a él ni le molestaban porque siempre mantenía contento y lo que le gustaba era mantener acompañado y de paso servirle a la gente, eso sí, para verlo más contento no era sino tenerle una buena jarra de café tibio no caliente y darle, eso era como meterle dinamita en la sangre, eso se convertía en superman, (risas). Cómo es la vida, en medio de todo, Vladimir le enseñaba a muchos sobre la honestidad y la sinceridad principalmente, él hablaba con cierta limitación, pero se hacía entender de lo que quería y sin palabras, él manifestaba quién era de su agrado más que otro, casi siempre era porque algunos lo molestaban y aveces le decían tontoniel y aunque no lo afectaba mucho, parecía que si sentía esa mala energía y mejor no frecuentaba esas personas, aunque cuando lo necesitaban siempre les ayudaba o les servía. La gente le regalaba ropa y él la regalaba a otros que también la necesitaban, mantenía con esos pantalones de jean rotos, manchados de plátano, tierra y todo lo que se unta uno en el campo por trabajar. La mamá, quedó viuda muy temprano al parecer, nunca le conocimos el esposo, cuando ella llegó a la vereda, al parecer venía de la vereda del Bosque, eso es en la Marina, muy retirada de aquí y su esposo como que murió de un golpe a caballo, como que le dejó una tierrita pero ella no quiso quedarse allá y vendió para comprar aquí él pedacito de tierra, porque es muy chiquitico lo que tiene, sin embargo les daba algo, más lo que hacía Vladimir, porque su hermanita estaba en primaria en la escuela de San José.

Él salía muy temprano, a recorrer las fincas que diariamente sacaban leche, esa era la primera actividad que hacía entre la 5 a 7 de la mañana, por lo general en el campo siempre se les da comida a los trabajadores, por lo que él no sufría por el desayuno, siempre en alguno de esos predios le daban el golpe. Luego de eso, cuando había cosecha de algún producto, se dedicaba a ir a cargarlo o a ayudar a cargar las mulas, él era muy bueno para eso, normalmente lo hacía solo y le montaba sin ayuda de nadie la carga a la mula las 10 arrobas solo, por lo que siempre era bien recibido por todos los que lo necesitaban. Cualquiera diría que Vladimir era todo un Hércules, pero no era así, en su fuerza sí, pero su cuerpo era más bien delgado, pero duro como un roble y bien marcado. No sufría de nada, ese man no lo veía uno enfermo, o con alguna dolencia y cuando no se veía por el pueblo, en los caminos o alguna finca, todo el mundo preguntaba por él, cosas que por lo regular no pasaban, sin embargo, aveces se quedaba haciendo algo en su parcela por encargo de su mamá, 
En el pueblo, cada nada se veía la presencia del ejército, lo que era un problema para la gente, porque quien los atendiera, era declarado informante y sino los atendían, eran declarados colaboradores de la guerrilla, como quien dice; palo porque bogas y palo porque no bogas, eso era muy hijueparriba, vivir en esa situación, pero ¿quién les decía algo?...nadies, todos nos quedábamos callados la jeta, o eso era una sentencia de muerte, pero lo más tenaz era que cuando llegaban los unos o los otros no se podía hacer ni mierda, solo aceptar que llegaran y esperar atenerse a las consecuencias. Todo esto afectó la producción, la comercialización de los productos se convirtió en un problema, porque casi siempre eran tildándonos de un lado o de otro. Entre esos militares que se radicaron en la vereda, en una casa construida por ellos, algo así como una caseta, que habitaban por periodos, estaba un sargento de apellido Bocanegra y unos soldados profesionales, entre ellos uno que era más malo que la carne de cabeza, de apellido Barreto. Este soldado, le gustaba extender la ruana pa formar problemas, entraba en las tiendas y pedía gaseosa, mantecadas y otras cosas y se hacía él pendejo para pagar, todo lo quería regalado, sin tener en cuenta que nadie les podía ofrecer nada, porque eso era motivo más que suficiente para que la guerrilla lo sentenciara a uno.

El viernes 26 de noviembre de 1999, llegó otro grupo de soldados que para reforzar a los que estaban radicados ahí, ellos eran muchos y venían con toda la violencia y altanería, a todos nos decían que éramos guerrilleros camuflados. Nos ofendían diciéndonos groserías y preguntándonos que en donde estaban los amiguitos. Todo esto sucedió temprano como a eso de las 6 de la mañana, hasta cuando se fueron a otras veredas más arriba de la nuestra, allá estuvieron todo el día y solamente regresaron en horas de la tarde, a dormir en donde estaba la casa temporal. Se rumoraba que ellos venían para sacar la guerrilla a como diera lugar, pero así mismo se conoció que cuando bajaron de los otros lugares, no encontraron a nadie, ni hubo ningún enfrentamiento.

El sábado 27, como era de costumbre Vladimir se levantó muy temprano a recogernos la leche para colocarla en él camino, al igual que en las otras fincas. Siendo más o menos a eso de las 5.30, se escucharon varios disparos, ahí cerca de la finca nuestra y la de otro vecino, todos nos refugiamos porque nos imaginamos que venía la guerrilla o que se habían enfrentado a raíz de haber estado por allá buscándolos, pero la verdad es que no se escuchó sino esos disparos. Los vecinos y yo, 

que Vladimir no llegó como era de costumbre por la leche y me quedé esperando que la recogiera.

Cuando llegamos al lugar de donde más o menos se habían escuchado los disparos, encontramos que había un cuerpo con vestido de militar, con un fusil y unas granadas en el suelo, todo

ensangrentado. La sorpresa fue brutal para todos, era Vladimir que estaba muerto y tirado como un perro en el piso, le habían pegado no sé cuántos tiros, pero lo dejaron como un colador. Esto sucedió al pie de la casa de unos vecinos de apellido Vargas, una familia que vio prácticamente todo lo que sucedió.

Ante todo, lo que estaba pasando y al encontrar lleno de toda la tropa el lugar, los mismos que habían llegado y los que ya estaban allí, les preguntamos qué había pasado, para lo que respondieron que se habían bajado a ese guerrillero hijueputa que los venía a joder. Todo quedamos aterrado, porque sabíamos que eso tenía algo de raro, es más nadies creía esa situación, puesto que todos conocíamos a Vladimir y en sus 33 años, y el tiempo que convivió con nosotros nunca le vimos hacer algo diferente o que estuviera al margen de la ley, más por su completa incapacidad mental. La familia Vargas, con él tiempo contó lo sucedido, y solamente atinaron a decir que el

Sargento Bocanegra, con el soldado Barreto, lo habían matado, cuando él se dirigía a recoger la leche y que habían visto cuando le colocaron un camuflado, el fusil y las granadas y que la ropa de él se la llevaron. Ellos afirmaron que Bocanegra le había dicho al soldado Barreto cuando le disparó sin motivo alguno, ese man era el lechero."

Estos tres relatos, no son el resultado de la imaginación de un escritor, la fantasía de un novelista o de un cuento reforzado para generar noticias. Es la realidad de un pueblo que, en su necesidad de vivir, tenía que soportar sin saber, consecuencias de causas que ni conocían, de luchas que no querían. Un pueblo que, ingenuamente, se callaba ante los gritos estridentes de la rodante muerte, que con su guadaña no hacía miramiento alguno en su selección de partida.

Esto y más, soportaron durante muchos años y lo siguen haciendo, nuestros campesinos, los mismos que en la Constitución Política, tienen mención limitada, debiendo tener de honor. Esos trabajadores de la tierra, que no les importa si es plana o de cordillera, porque aprendieron el valor de amarla, el valor de respetarla sin condición alguna, a entender que la violencia territorial, no la crearon ellos y que los espacios para unos en el plan y para otros en el monte, no fueron reservados para que se derramara su sangre. 


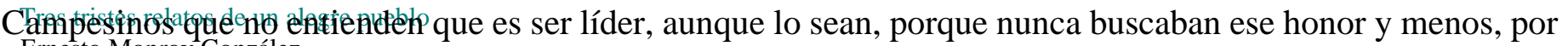
Ernesto Monroy González

el cual hoy se les cobra con sus vidas. Nuevamente hoy, más que nunca, se escucha ese silencioso llanto, hoy más que nunca se reclama a la muerte que cambie esa guadaña por la vara de Esculapio, para que seleccione no quien parte, sino quien se queda.

\section{Referencias bibliográficas}

Monroy, E. (2018). Actividad y Desarrollo de las Asociaciones Campesinas Agropecuarias: Un Estudio de Caso en el Municipio de Chaparral - Tolima. Universidad del Tolima. 